\title{
CARACTERÍSTICAS DA ARBORIZAÇÃO DOS BAIRROS CADORIN, PARZIANELLO E LA SALLE EM PATO BRANCO - PR (2007)
}

\author{
Danielle Acco Cadorin ${ }^{1}$, Lenir Maristela Silva ${ }^{2}$, Ionete Hasse ${ }^{3}$, Celso Ferraz Bett ${ }^{4}$, Aquelis \\ Armiriato Emer ${ }^{4}$, Juliano Rossi de Oliveira ${ }^{4}$
}

(recebido em 26.09.2008 e aceito para publicação em 03.12.2008)

\begin{abstract}
RESUMO
Este trabalho apresenta os resultados e a análise dos inventários da arborização de vias públicas dos bairros Cadorin, Parzianello e La salle de Pato Branco - PR, realizados em 2007. Apenas duas espécies não foram identificadas. Os dados de cada espécime foram coletados por amostragem e anotados em planilha. Obteve-se também a freqüência relativa de cada espécie. Foram inventariados 2036 indivíduos arbóreos vivos, dos quais 1677 eram indivíduos adultos e contabilizaram 55 espécies identificadas. A análise dos resultados obtidos mostra que, das 55 espécies inventariadas, 25 são nativas e apenas 11 pertencem ao bioma local (floresta ombrófila mista). Nos bairros Cadorin, Parzianello e La Salle ocorreram, respectivamente, 49,99\%, 11,18\% e 17,92\% de freqüência de indivíduos nativos do Brasil. Os resultados também mostraram que há predomínio de cinco espécies perante as demais, sendo: Ligustrum lucidum (ligustro), Lagerstroemia indica (extremosa), Schinus molle (aroeira), Bauhinia variegata (pata de vaca) e Tipuana tipu (tipuana). Dessas espécies, Ligustrum lucidum (ligustro) é a mais freqüente, encontrada nos três bairros, sendo responsável por $42,84 \%$ da arborização viária dos mesmos. A maioria dos indivíduos analisados possui uma boa área livre e não receberam poda na ocasião do inventário. Dentre as poucas podas observadas, destacam-se podas drásticas e podas em $\mathrm{V}$.
\end{abstract}

Palavras-chave: arborização urbana; inventário; Ligustrum lucidum.

\footnotetext{
${ }^{1}$ Acadêmica do Curso de Agronomia, UTFPR, Pato Branco - PR, Endereço: Via do Conhecimento, Km1, Pato Branco - PR, Cep: 85503-390, <danikadorin@hotmail.com>;

${ }^{2}$ Doutora em Produção Vegetal, UTFPR, Pato Branco - PR, lenir@utfpr.edu.br;

${ }^{3}$ Doutora em Produção Vegetal, UTFPR, Pato Branco - PR, hasse@utfpr.edu.br;

${ }^{4}$ Acadêmicos do Curso de Agronomia, UTFPR, Pato Branco/PR.
} 


\title{
SOME FEATURES OF THE ARBORIZATION IN CADORIN, PARZIANELLO AND LA SALLE DISTRICTS IN PATO BRANCO-PR/2007
}

\begin{abstract}
The present essay demonstrates the results and the analyses of the arborization inventory on public streets in Cadorin, Parzianello and La Salle districts in Pato Branco-PR, taken in 2007. Only two species haven't been identified. The data of each specimen have been collected through samples and notes have been taken on a worksheet. The relative frequency of each species has also been taken. It had been catalogued 2036 live arboreous adult individuals and the amount of 55 species identified. The analyses of the results obtained, shows that, from the 55 catalogued species , 25 are actually native ones and 11 of them belongs to the local biome ( mixed ombrófila forest ). In the districts Cadorin, Parzianello and La Salle, occurred respectively 49, 99\%, 11, 18\% and 17, 29\% of native individuals from Brazil. The results also have shown that there is a predominance of five species over the rest, such as: Ligustrum lucidum (ligustro), Lagerstroemia indica (extremosa), Schinus mole (aroeira) , Bauhinia variegate (pata de vaca) and Tipuana Tipu ( tipuana). From the mentioned species, Ligustrum lucidum (ligustro) is the most common and appears more frequently, it had been found on the three districts, being responsible for 42 , $84 \%$ of the street arborization on them. The great majority of the analyzed individuals owns a very reasonable free area and was rid of cuttings by the research time. Among the few cuttings which had been observed, we could emphasize the drastic ones and the $\mathrm{V}$-shaped ones.
\end{abstract}

Key words: Urban arborization, inventory, Ligustrum lucidum 


\section{INTRODUÇÃO}

A arborização urbana é um serviço público que proporciona à população conforto ambiental, bem estar psíquico e psicológico, além de proporcionar beleza, por diminuir a dominância do concreto e do asfalto, introduzir elementos naturais, linhas suaves e orgânicas e proporcionar identidade às ruas. Age ainda atuando na melhoria do microclima, amenizando a poluição atmosférica e sonora e diminuindo a velocidade do vento (BIONDI e ALTHAUS, 2005).

A escolha de espécies adequadas para determinados locais que se deseja arborizar é fundamental no planejamento da arborização urbana. Uma escolha acertada significa o sucesso da implantação e a diminuição de posteriores gastos com tratos culturais e manutenção de árvores inseridas em local errado, sem planejamento anterior (GONÇALVES, 2004).

Por estes motivos, segundo Silva et al (2007), realizar inventários sobre a arborização das cidades é de fundamental importância para que se possa realizar qualquer planejamento, sendo importante também que se considerem as características climáticas e pedológicas específicas de cada lugar, não podendo, dessa maneira, apenas importar soluções de outros lugares e, principalmente, de regiões fitogeográficas diferentes.

Conforme Biondi e Althaus (2005), ruas homogêneas na arborização são suscetíveis a pragas e doenças, promovendo perdas ao meio urbano. Recomenda-se que, na composição da arborização das ruas de uma cidade, as populações individuais por espécies não ultrapassem 10 ou 15\% da população total; entretanto, o que ocorre é a presença quase total de uma única espécie.

No ano de 2005, deu-se início ao inventário da arborização viária da cidade de Pato Branco, quando foi realizado um levantamento no centro da cidade. Já em 2006, foi feito o censo nos bairros Bancários, Brasília e Pinheiros. No ano de 2007, prosseguindo com os estudos, deu-se início aos inventários dos bairros Cadorin, Parzianello e La Salle. Cerca de seis mil espécimes arbóreos foram analisados nesse período; dentre esses, chama a atenção o percentual elevado de espécimes exóticos (78,5\%). Além disso, diversos problemas foram identificados (MOCCELIN et al. 2006; SILVA, et al. 2007; HASSE, et al. 2008). Este trabalho apresenta os resultados e a análise dos inventários dos bairros Cadorin, Parzianello e La Salle. 


\section{MATERIAIS E MÉTODOS}

Os bairros Parzianello, Cadorin e La Salle localizam-se em Pato Branco/PR. Este município localiza-se na região sudoeste do Paraná, no terceiro planalto paranaense. Apresenta Cfa - clima subtropical úmido mesotérmico (IAPAR, 2000), destacando-se o solo do tipo latossolo vermelho distroférrico (EMBRAPA, 1999). Encontra-se a $760 \mathrm{~m}$ de altitude. A população total corresponde a 62.167 habitantes, sendo que, destes, 56.739, correspondem à população urbana (IBGE, 2000). A vegetação onde insere - se Pato Branco é típica da Floresta Ombrófila Mista Montana ou Floresta de Araucárias (IBGE, 1992).

Para localização das vias públicas e a obtenção de suas extensões, foi utilizada uma planta planialtimétrica na escala 1:10.000, elaborada pelo IPPUPB (Instituto de Pesquisa e Planejamento Urbano de Pato Branco).

Todas as espécies foram identificadas. Contudo, a coleta de dados de cada espécime foi feita por amostragem, ou seja, para cada rua, foram contados todos os espécimes arbóreos e identificadas as espécies. Foram escolhidos quatro espécimes de cada espécie. Quando não houve quatro indivíduos de determinada espécie, em determinada rua, foram coletados os dados do número de espécimes existentes. Somente foram examinadas as árvores com DAP (diâmetro a altura do peito) igual ou maior de 0,10 $\mathrm{m}$. Os dados coletados foram o tipo de poda realizada e o tamanho de área livre de pavimentação em torno da árvore.

Quanto aos dados da planilha, é importante esclarecer que o tipo de rua pode corresponder a residencial, comercial, sem ocupação ou de uso misto; a espécie foi identificada pelo nome vulgar e pelo nome científico.

A freqüência relativa de cada espécie foi calculada por meio da razão entre o número de indivíduos da espécie e o número total de indivíduos do bairro, multiplicada por 100.

\section{RESULTADOS E DISCUSSÃO}

Nas quarenta e nove ruas inventariadas, foram encontrados 2036 indivíduos arbóreos vivos, dos quais 1677 eram indivíduos adultos que contabilizaram 55 espécies e 2 não identificadas.

Conforme os dados mostrados (Tabela 01), percebe-se que, nos três bairros, há um predomínio significativo de uma única espécie diante das demais. O bairro Cadorin possui $30,98 \%$ da sua arborização viária composta pela espécie Schinus molle; o bairro Parzianello e La Salle possuem, respectivamente, $45,63 \%$ e 47,29\% da arborização viária composta pela espécie Ligustrum lucidum. 
Tabela1. Freqüência das espécies presentes na arborização viária dos bairros Cadorin, Parzianello e La Salle de Pato Branco - PR (2007).

\begin{tabular}{|c|c|c|c|c|c|c|c|}
\hline Nome Vulgar & Nome Científico & Cadorin & Freq. & Parzianello & Freq. & La Salle & Freq. \\
\hline Abacateiro & Persea americana Mill. & 0 & $0 \%$ & 0 & 0 & 1 & $0,09 \%$ \\
\hline Acássia Negra & $\begin{array}{l}\text { Acacia podalyriifolia } \\
\text { Cunn. Ex G. Don. }\end{array}$ & 3 & $1,63 \%$ & 0 & - & 0 & - \\
\hline Aleluia & $\begin{array}{l}\text { Senna multijuga (Rich.) } \\
\text { Irwin et. Barn }\end{array}$ & 1 & $0,54 \%$ & 0 & - & 3 & $0,27 \%$ \\
\hline Amora & Morus alba L. & 2 & $1,09 \%$ & 7 & $1,92 \%$ & 3 & $0,27 \%$ \\
\hline Araçá & $\begin{array}{c}\text { Psidium cattleianum } \\
\text { Sabine }\end{array}$ & 1 & $0,54 \%$ & 4 & $1,09 \%$ & 4 & $0,35 \%$ \\
\hline Araucária & $\begin{array}{l}\text { Araucaria angustifolia } \\
\text { (Bertol.) Kuntze }\end{array}$ & 1 & $0,54 \%$ & 1 & $0,27 \%$ & 1 & $0,09 \%$ \\
\hline Ariticum & $\begin{array}{c}\text { Rollinia silvatica (St. Hil.) } \\
\text { Mart. }\end{array}$ & 2 & $1,09 \%$ & 0 & - & 5 & $0,44 \%$ \\
\hline Aroeira Mansa & Schinus molle L. & 57 & $30,98 \%$ & 11 & $3,02 \%$ & 61 & $5,41 \%$ \\
\hline Aroeira Vermelha & $\begin{array}{c}\text { Schinus terebinthifolius } \\
\text { Raddi }\end{array}$ & 0 & - & 0 & - & 3 & $0,27 \%$ \\
\hline Caliandra & $\begin{array}{c}\text { Calliandra brevipes } \\
\text { Benth. }\end{array}$ & 0 & - & 1 & $0,27 \%$ & 5 & $0,44 \%$ \\
\hline Camélia & Camellia japonica L. & 0 & - & 0 & - & 1 & $0,09 \%$ \\
\hline Canafístula & $\begin{array}{l}\text { Peltophorum dubium } \\
\text { (Spreng.) Taub. }\end{array}$ & 0 & - & 4 & $1,09 \%$ & 0 & - \\
\hline Canela & $\begin{array}{c}\text { Ocotea porosa (Nees) L. } \\
\text { Barroso }\end{array}$ & 0 & - & 2 & $0,55 \%$ & 3 & $0,27 \%$ \\
\hline Cânfora & $\begin{array}{c}\text { Cinnamomum camphora } \\
\text { L. }\end{array}$ & 0 & - & 0 & - & 1 & $0,09 \%$ \\
\hline Cedro & Cedrela fissilis Vell. & 2 & $1,09 \%$ & 1 & $0,27 \%$ & 1 & $0,09 \%$ \\
\hline Cerejeira & Prunus serrulata Lindl. & 0 & - & 0 & - & 4 & $0,35 \%$ \\
\hline Champaca & Michelia champaca L. & 0 & - & 1 & $0,27 \%$ & 8 & $0,71 \%$ \\
\hline Cinamomo & Melia azedarach L. & 7 & $3,80 \%$ & 2 & $0,55 \%$ & 8 & $0,71 \%$ \\
\hline Cipreste & Cupressus sp. & 2 & $1,09 \%$ & 1 & $0,27 \%$ & 20 & $1,77 \%$ \\
\hline Citrus & Citrus sp. & 7 & $3,80 \%$ & 13 & $3,56 \%$ & 29 & $2,57 \%$ \\
\hline Erva Mate & Ilex paraguariensis St. Hil. & 1 & $0,54 \%$ & & - & 6 & $0,53 \%$ \\
\hline Extremosa & Lagerstroemia indica L. & 9 & $4,89 \%$ & 58 & $15,89 \%$ & 168 & $14,91 \%$ \\
\hline Falsa Canela & $\begin{array}{c}\text { Cinnamomum zeylanicum } \\
\text { (Breyn.) Bl. }\end{array}$ & 0 & - & 1 & $0,27 \%$ & 13 & $1,15 \%$ \\
\hline Falsa Seringueira & $\begin{array}{c}\text { Ficus elastica Roxb. ex } \\
\text { Hornem. }\end{array}$ & 0 & - & 0 & - & 1 & $0,09 \%$ \\
\hline Ficus & Ficus sp. & 0 & - & 0 & - & 10 & $0,89 \%$ \\
\hline Flamboyant & $\begin{array}{c}\text { Delonix regia (Bojer ex } \\
\text { Hook.) Rafin. }\end{array}$ & 0 & - & 0 & - & 4 & $0,35 \%$ \\
\hline Goiaba & Psidium guajava L. & 1 & $0,54 \%$ & 4 & $1,09 \%$ & 2 & $0,18 \%$ \\
\hline Grevílea & $\begin{array}{l}\text { Grevillea robusta A. } \\
\text { Cunn. Ex R. Br. }\end{array}$ & 0 & - & 5 & $1,37 \%$ & 6 & $0,53 \%$ \\
\hline
\end{tabular}


Tabela 1. Continuação...

\begin{tabular}{|c|c|c|c|c|c|c|c|}
\hline Nome Vulgar & Nome Científico & Cadorin & Freq. & Parzianello & Freq. & La Salle & Freq. \\
\hline Guapuruvu & $\begin{array}{l}\text { Schizolobium parahyba, } \\
\text { Vell. }\end{array}$ & 0 & - & 0 & - & 1 & $0,09 \%$ \\
\hline Hibisco & Hibiscus sinensis L. & 0 & - & 2 & $0,55 \%$ & 3 & $0,27 \%$ \\
\hline Ingá & Inga laurina (Sw.) Willd. & 0 & - & & - & 3 & $0,27 \%$ \\
\hline Ipê Amarelo & $\begin{array}{l}\text { Tabeuia alba (Cham.) } \\
\text { Sandw. }\end{array}$ & 0 & - & 0 & - & 3 & $0,27 \%$ \\
\hline $\begin{array}{l}\text { Ipê Amarelo } \\
\text { Miúdo }\end{array}$ & $\begin{array}{l}\text { Tabebuia chrysotricha } \\
\text { (Mart. ex. DC.) Standl. }\end{array}$ & 1 & $0,54 \%$ & 13 & $3,56 \%$ & 20 & $1,77 \%$ \\
\hline Ipê Roxo & $\begin{array}{l}\text { Tabebuia heptaphylla } \\
\text { (Vell.) Tol. }\end{array}$ & 5 & $2,72 \%$ & 0 & - & 16 & $1,42 \%$ \\
\hline Jabuticabeira & $\begin{array}{c}\text { Plinia trunciflora (O.Berg) } \\
\text { Kausel. }\end{array}$ & 4 & $2,17 \%$ & 1 & $0,27 \%$ & 21 & $1,86 \%$ \\
\hline Ligustro & $\begin{array}{c}\text { Ligustrum lucidum W. T. } \\
\text { Aiton }\end{array}$ & 18 & $9,78 \%$ & 167 & $45,75 \%$ & 533 & $47,29 \%$ \\
\hline Manduírana & $\begin{array}{l}\text { Senna macranthera } \\
\text { (Collad.) Irwin et. Barn }\end{array}$ & 0 & - & 0 & - & 3 & $0,27 \%$ \\
\hline Nêspera & $\begin{array}{l}\text { Eriobotrya japonica } \\
\text { (Thunb.) Lindl. }\end{array}$ & 6 & $3,26 \%$ & 6 & $1,64 \%$ & 3 & $0,27 \%$ \\
\hline Palmeira & Euterpe oleracea Mart. & 2 & $1,09 \%$ & 0 & - & 1 & $0,09 \%$ \\
\hline Pata de Vaca & Bauhinia variegata L. & 15 & $8,15 \%$ & 23 & $6,30 \%$ & 60 & $5,32 \%$ \\
\hline $\begin{array}{c}\text { Pata de Vaca do } \\
\text { Mato }\end{array}$ & Bauhinia forficata Link & 0 & - & 0 & - & 3 & $0,27 \%$ \\
\hline Pau Brasil & $\begin{array}{c}\text { Caesalpinia echinata } \\
\text { Lam. }\end{array}$ & 0 & - & 0 & - & 7 & $0,62 \%$ \\
\hline Pau Incenso & Pittosporum undulatum & 2 & $1,09 \%$ & 2 & $0,55 \%$ & 0 & - \\
\hline Pessêgo & $\begin{array}{c}\text { Prunus persica (L.) } \\
\text { Batsch }\end{array}$ & 2 & $1,09 \%$ & 2 & $0,55 \%$ & 0 & - \\
\hline Pitanga & Eugenia uniflora L. & 17 & $9,24 \%$ & 4 & $1,09 \%$ & 20 & $1,77 \%$ \\
\hline Primavera & Bougainvillea glabra & 1 & $0,54 \%$ & & & 0 & \\
\hline Quaresmeira & $\begin{array}{c}\text { Tibouchina granulosa } \\
\text { Cogn. } \\
\end{array}$ & 0 & - & 1 & $0,27 \%$ & 7 & $0,62 \%$ \\
\hline Sete Capotes & $\begin{array}{l}\text { Campomanesia } \\
\text { guazumaefolia L. }\end{array}$ & 0 & - & 0 & - & 1 & $0,09 \%$ \\
\hline Sete Copas & Terminalia catappa L. & 0 & - & 0 & - & 1 & $0,09 \%$ \\
\hline Sibipiruna & $\begin{array}{c}\text { Caesalpinia } \\
\text { peltophoroides Benth. }\end{array}$ & 0 & - & 0 & - & 6 & $0,53 \%$ \\
\hline Tipuana & $\begin{array}{c}\text { Tipuana tipu (Benth.) } \\
\text { Kuntze }\end{array}$ & 15 & $8,15 \%$ & 28 & $7,67 \%$ & 42 & $3,73 \%$ \\
\hline Uva Japão & Hovenia dulcis Thunb. & 0 & - & 0 & - & 1 & $0,09 \%$ \\
\hline Vacum & Allophylus edulis Radlk. & 0 & - & 0 & - & 1 & $0,09 \%$ \\
\hline \multicolumn{2}{|c|}{ TOTAL DE ESPÉCIMES } & 184 & $100 \%$ & 365 & $100 \%$ & 1127 & $100 \%$ \\
\hline
\end{tabular}

Segundo Pereira et al (2005), o fato de haver predominância de poucas espécies na arborização de vias públicas traz sérias conseqüências para a biodiversidade do ecossistema urbano, considerando-se que a diversidade da vegetação é de suma importância para a ampliação e fixação da fauna e a manutenção do equilíbrio biológico. É 
importante lembrar que os pássaros não se alimentam apenas de frutos, sendo preciso diversificar o quanto mais a vegetação, subsidiando a fauna por meio das flores.

Segundo Melo e Romani (2008) a diversificação de espécies arbóreas recomendadas para o plantio deve ser selecionada de tal forma que propicie mais cor, visibilidade, conforto térmico, alimento para a fauna e proteção, possibilitando ao usuário desfrutar de um ambiente integrado à paisagem nativa, à conservação e preservação da vegetação, bem como comprometendo-o com a responsabilidade social que tem em relação ao ambiente.

Biondi e Althaus (2005) recomendaram que uma única espécie não ultrapasse o total de 10 a 15\% de indivíduos arbóreos contidos em uma cidade. Em ruas com plantios homogêneos, as árvores correm o risco de se tornarem alvo fácil de pragas e doenças, o que acarreta perdas para o meio urbano.

Verifica-se, na Tabela 01, que o bairro La Salle possui a maior diversificação entre os três bairros, contendo 48 diferentes espécies, porém, somente 22 delas são nativas, e apenas cinco espécies são responsáveis por 76,66\% da arborização do bairro. Isso acusa a ocorrência de uma má distribuição das espécies no local, o que também acontece nos bairros Cadorin e Parzianello, que contam, respectivamente, com 58,15\% e 78,96\% da arborização composta por apenas cinco espécies (Figura 01).

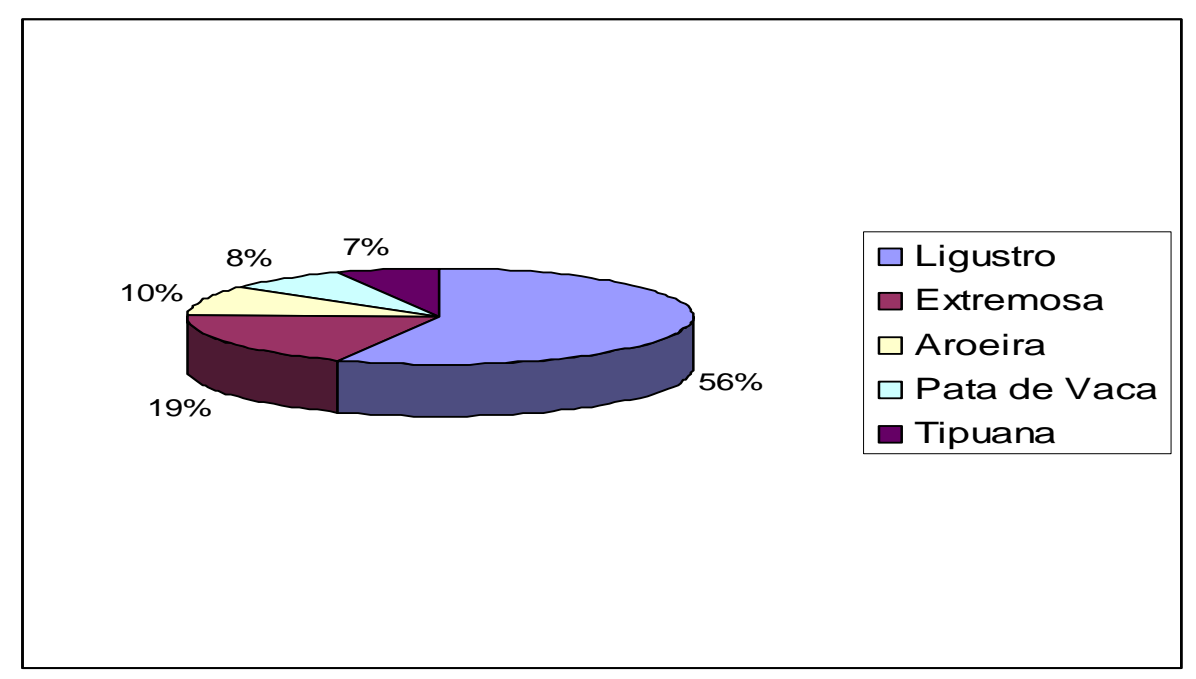

Figura 1. Freqüência das cinco espécies arbóreas mais abundantes nos bairros Cadorin, Parzianello e La Salle de Pato Branco - PR (2007).

Das cinco espécies mais abundantes nos três bairros, apenas uma é nativa e pertence à Floresta Ombrófila Mista, a Aroeira mansa (Schinus molle), e há um significativo predomínio da espécie Ligustrum lucidum.

Nos três bairros, há maior freqüência de espécimes exóticos do que nativos, sendo que, no Parzianello e no La Salle, este número é muito maior. Dentre os espécimes exóticos 
listados, estão presentes seis espécies que constam na lista de exóticas invasoras do Brasil (IAP, 2007). Das 55 espécies inventariadas, 25 são nativas e apenas 11 pertencem ao bioma local (Floresta Ombrófila Mista). Apesar do número de espécies nativas representar $45,45 \%$ do total de espécies presentes nos três bairros, a freqüência de indivíduos arbóreos nativos é muito baixa em relação aos indivíduos exóticos (Tabela 02).

Tabela 2. Relação entre a freqüência dos espécimes nativos e exóticos presentes nos bairros Cadorin, La Salles e Parzianello de Pato Branco - PR (2007).

\begin{tabular}{c|c|c}
\hline Bairros & Espécimes Nativos & Espécimes Exóticos \\
\hline Cadorin & $49,99 \%$ & $50,01 \%$ \\
\hline Parzianello & $11,18 \%$ & $88,82 \%$ \\
\hline La Salle & $17,92 \%$ & $82,08 \%$ \\
\hline
\end{tabular}

Conforme Machado et al (2006), a crescente substituição de espécies nativas por espécies exóticas nas cidades brasileiras altera o ambiente natural que resta dos centros urbanos. Este procedimento acaba por uniformizar a paisagem de diferentes cidades e contribuir para a redução da biodiversidade no ambiente urbano, dissociando-se do contexto ambiental onde se insere.

Segundo Ziller (2001), a invasão por plantas exóticas afeta o funcionamento natural do ecossistema, pois elas competem e podem eliminar as plantas nativas, diminuindo a biodiversidade. O potencial de espécies exóticas de alterar sistemas naturais é tão grande que as plantas invasoras são, hoje, a segunda maior ameaça mundial à biodiversidade perdendo somente para a destruição direta pelo homem. Os processos de invasão agravam-se à medida que as plantas exóticas ocupam o espaço das nativas. As conseqüências principais são a perda da biodiversidade e a modificação dos ciclos e características naturais dos ecossistemas atingidos, além da alteração fisionômica da paisagem natural, podendo causar grandes prejuízos econômicos.

Segundo Reis et al. (2003), projetos de arborização urbana podem criar modelos com réplicas dos modelos vegetacionais regionais, como agrupamentos arbóreos com grande número de epífitas e lianas imitando os extratos das florestas, e desta forma, expressando a biodiversidade, que deve ser um valor cultural reconhecido dentro do meio urbano.

Os dados do censo realizado nos bairros Parzianello e La Salle mostram que quase metade de sua arborização viária é composta pela espécie Ligustrum lucidum.(ligustro). Esta espécie é exótica e consta na lista das espécies invasoras brasileiras (IAP, 2007)

Resultados parecidos foram obtidos no inventário realizado nos bairros Brasília e Bancários de Pato Branco, em que a freqüência da espécie foi de 40,65\% e 70,14\%, respectivamente (RODIGHIERO e SILVA, 2007). O mesmo foi evidenciado no inventário do 
centro de Pato Branco, que apresentou uma freqüência de $62,4 \%$ de Ligustrum lucidum (SILVA et al., 2007). Em inventário realizado na avenida central da cidade de Mariópolis, também localizada no Sudoeste do Paraná, constatou-se freqüência de 54,01\% da espécie (SILVA et al. 2008).

Esta espécie, de origem asiática, é amplamente usada nas cidades do Sul do Brasil e foi introduzida no país para fins ornamentais. Sua dispersão ocorre de maneira rápida e é capaz de competir e impedir a regeneração de plantas nativas. Os frutos são tóxicos para os humanos e podem causar sintomas como náusea, dores de cabeça, dores abdominais, vômitos, diarréia, pressão baixa e hipotermia. Atualmente, a espécie é uma invasora da Floresta Ombrófila Mista Aluvial no Estado do Paraná e está em processo de dominância de várias áreas de floresta ciliar da região (INSTITUTO HÓRUS DE DESENVOLVIMENTO E CONSERVAÇÃO AMBIENTAL, 2006).

A terceira espécie com maior freqüência - Schinus molle. (Aroeira mansa) - é a única espécie nativa e do bioma local dentre as cinco, porém, por causa de sua ramificação pendente, ela pode dificultar a passagem de pedestres pelas calçadas (SANTOS e TEIXEIRA, 2001).

Conforme Santos e Teixeira (2001), área livre pode ser definida como o espaço livre de pavimento que permite a infiltração de águas e nutrientes. A falta de área livre provoca um mau desenvolvimento das plantas, e a utilização de espécies de sistema radicular superficial em área reduzida gera trincas e compromete o piso, em decorrência da pressão exercida pelas raízes. Recomenda-se que a área livre não seja menor que $1 \mathrm{~m}^{2}$.

A maioria dos indivíduos inventariados possui uma boa área livre; ainda assim, o bairro La Salle apresenta um alto número de indivíduos com pouca ou nenhuma área livre, somando 54\% das árvores que não possuem espaço suficiente para as raízes se desenvolverem (Figura 02). Resultados diferentes foram obtidos no inventário do centro de Pato Branco, em que $78 \%$ dos indivíduos apresentam nenhuma ou uma pequena área livre ao seu redor (MOCCELLIN et al, 2006). Tais dados mostram que pode haver uma relação entre manejo e cuidado com as árvores e o perfil do bairro em que estão inseridas, pois, no centro, onde prevalece o comércio, há menos área livre de pavimentação do que nos bairros aqui analisados, tipicamente residenciais. 


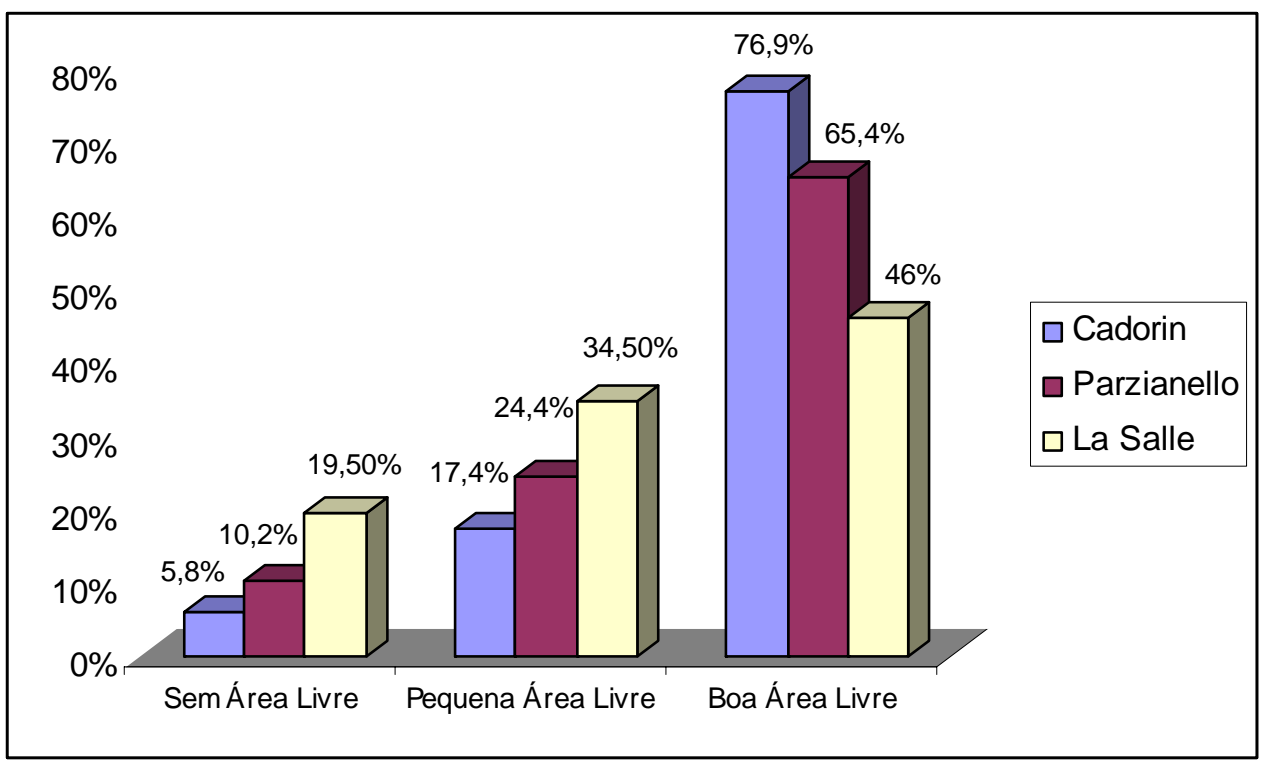

Figura 2. Freqüência dos tamanhos de áreas livres de pavimentação dos indivíduos arbóreos dos bairros Cadorin, Parzianello e La Salle de Pato Branco - PR (2007).

Segundo Langowski e Klechowicz (2001), árvores com área totalmente impermeabilizada ao redor do tronco, sem nenhuma área livre ou mesmo com área livre insuficiente, são muito prejudicadas e podem morrer por falta de água, sufocamento ou estrangulamento. Além disso, a impermeabilização exagerada dos solos nas cidades tem contribuído muito para a ocorrência de enchentes.

A poda é uma antiga prática, realizada em jardins clássicos europeus ou em frutíferas, visando a uniformizar a produção de frutas. Por causa desta cultura, nas cidades, ainda há uma tradição de muitas pessoas fazem a poda com fins estéticos ou por acreditarem que a poda poderá revigorar a árvore. Entretanto, estas podas causam estresse e deixam áreas expostas passíveis de entrada de patógenos (PIVETTA e SILVA FILHO, 2002). Pela abrangência deste ato, a poda pode ser considerada um problema cultural, já que nem todas as espécies precisam ser podadas ou aceitam a poda (SANTOS e TEIXEIRA, 2001).

Pode-se perceber que a maioria dos indivíduos dos três bairros não recebeu poda na ocasião do inventário (Figura 03). Dentre as poucas podas observadas, destacam-se podas drásticas e podas em $\mathrm{V}$. Resultados parecidos foram obtidos no inventário do Centro e nos bairros Brasília, Bancários e Pinheiros (MOCCELLIN et al, 2006; RODIGHIERO e SILVA, 2007). Contudo, no Centro, após o inventário ter sido realizado, a prefeitura efetuou ações de poda e todas elas de modo drástico (observação visual). 


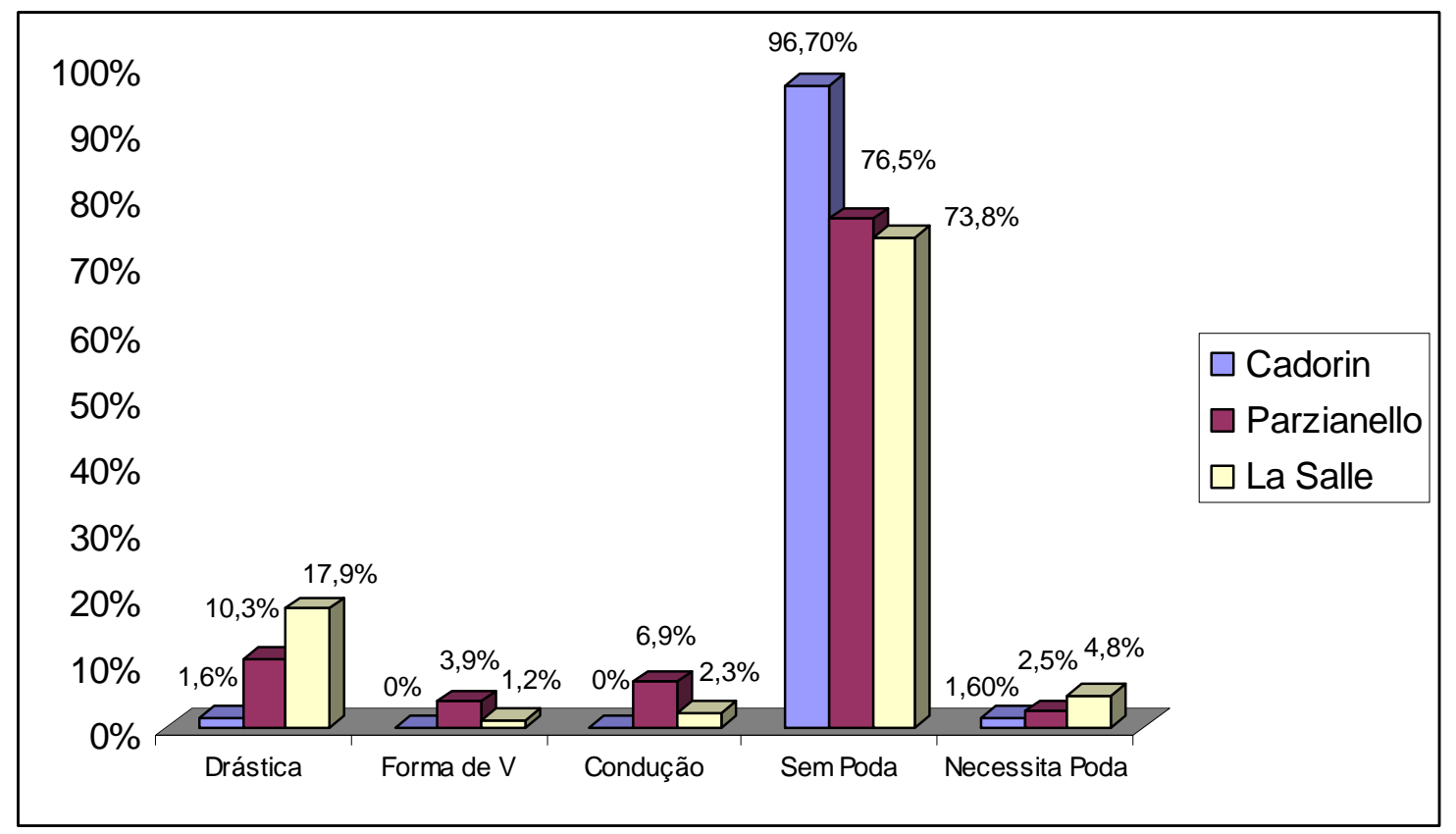

Figura 3. Freqüência dos tipos de podas realizadas nos indivíduos arbóreos dos bairros Cadorin, Parzianello e La Salle de Pato Branco - PR (2007).

Segundo o DEPAVE (Departamento de Parques e Áreas Verdes de São Paulo), citado por Pivetta e Silva Filho (2002) "a poda é uma cirurgia e, como toda cirurgia, deve ser evitada". A poda, além de interferir na estética e na fisiologia da planta, é uma operação perigosa, podendo causar diferentes acidentes; portanto, é uma operação que deve ser minimizada, e o mais eficiente procedimento é a criteriosa escolha das espécies a serem plantadas.

Em Pato Branco, a rede elétrica é do tipo convencional, possuindo condutores nus, que, quando em contato com a árvore, muitas vezes, causam curto-circuito e, consequentemente, interrupção do fornecimento de energia. Os conflitos entre árvores e a rede de energia são o principal motivo que leva à realização de podas drásticas. A Rede Compacta Protegida mostra-se uma solução para o convívio harmonioso entre a rede elétrica e a arborização viária, já que esse tipo de rede não exige podas severas das árvores e, com seu uso, é possível reduzir as interrupções no fornecimento de energia, sendo a solução mais econômica para solucionar o problema (COMPANHIA PARANAENSE DE ENERGIA, 2005).

\section{CONCLUSÕES}

A análise dos resultados obtidos mostra que, das 55 espécies inventariadas, 25 são nativas e apenas 11 pertencem ao bioma local (Floresta Ombrófila Mista). Apesar do número de espécies nativas representar $45,45 \%$ do total de espécies presentes nos três 
bairros, a freqüência de indivíduos arbóreos nativos é muito baixa em relação a dos indivíduos exóticos. Nos bairros Cadorin, Parzianello e La Salle, ocorrem, respectivamente 49,99\%, 11,18\% e 17,92\% de indivíduos nativos do Brasil.

Os resultados também mostram que há predomínio de cinco espécies perante as demais, sendo essas: Ligustrum lucidum (ligustro), Lagerstroemia indica. (extremosa), Schinus molle. (aroeira), Bauhinia variegata. (pata de vaca) e Tipuana tipu (tipuana).

Falta de área livre de pavimentação na base do tronco foi um problema frequentemente encontrado nos bairros inventariados. Também se observaram conflitos entre a copa das árvores e a rede de energia elétrica, que resultaram, em muitos casos, na realização de poda drástica dos indivíduos arbóreos. Para este problema, recomenda-se a adesão ao sistema de redes compactas protegidas, que proporciona convívio harmonioso entre árvores e rede elétrica.

\section{REFERÊNCIAS BIBLIOGRÁFICAS}

BIONDI, D. e ALTHAUS, M. Árvores de Rua de Curitiba: Cultivo e Manejo. Curitiba: FUPEF: 2005.

COMPANHIA PARANAENSE DE ENERGIA. Concepção da Rede Compacta Protegida. Disponível em: http://www.copel.com/pagcopel.nsf/docs. Acesso em: 18/05/2005.

EMBRAPA - EMPRESA BRASILEIRA DE PESQUISA AGROPECUÁRIA - Centro Nacional de Pesquisa de Solos. Sistema Brasileiro de Classificação de Solos. Brasília: EMBRAPA, 1999. 412 p.

GONÇALVES, W. Árvores para o ambiente urbano. Viçosa: Aprenda fácil, 2004.

HASSE, I.; SHINOSAKA, T. J.; SILVA, L. M. Avaliação da presença de cupins na arborização da região central de Pato Branco/PR. Revista da Sociedade Brasileira de Arborização Urbana, v. 3, N. 1 p. 9-18, 2008.

IAP - Instituto Ambiental do Paraná. Lista Oficial de Espécies Exóticas Invasoras para o Estado do Paraná. 2007. Disponível em: http://www.pr.gov.br/iap. Acesso em: 25/03/08.

IAPAR - INSTITUTO AGRONÔMICO DO PARANÁ. Cartas climáticas do Paraná. Londrina: IAPAR, 2000. CD-ROM.

IBGE. Manual técnico da vegetação brasileira. Rio de Janeiro: Fundação Instituto Brasileiro de Geografia e Estatística, Série Manuais Técnicos em Geociências, 1992. 92p.

IBGE - INSTITUTO BRASILEIRO DE GEOGRAFIA E ESTATÍSTICA. Atlas do senso demográfico. Rio de Janeiro: IBGE, 2000. 127p.

INSTITUTO HÓRUS DE DESENVOLVIMENTO E CONSERVAÇÃO AMBIENTAL. Espécies exóticas invasoras: fichas técnicas. 2006. Disponível em: http://www.institutohorus.org.br. Acesso em: 13/03/2008.

LANGOWSKI, E.; KLECHOWICKZ, N. A. Manual Prático de Poda: manual prático de poda e arborização urbana. Cianorte: APROMAC, 2001. 40p. 
MACHADO, R, R, B et al. Árvores Nativas para a Arborização de Teresina - PIAUÍ. Revista da Sociedade Brasileira de Arborização Urbana, v.1, n.1, p. 10-18, 2006.

MELO, E, F, R, Q.; ROMANI, A. Praça Ernesto Tocheto: Importância da sua Preservação Histórica e Aspectos de sua Arborização. Revista da Sociedade Brasileira de Arborização Urbana. Piracicaba, v.3, n.1, p. 54-72. , mar. 2008.

MOCCELLIN, R.; SILVA, L. M.; WEISSHEIMER, D. I.; ZBORALSKI, A. R.; FONSECA, L. Situação da arborização do centro da cidade de Pato Branco - PR. In: XI Seminário de Iniciação Cientifica e Tecnológica - Universidade Tecnológica Federal do Paraná, 2006. Anais...Curitiba, CD-ROM.

PEREIRA et al. O Uso de Espécies Vegetais, como Instrumento de Biodiversidade da Avifauna Silvestre, na Arborização Pública: o caso de Recife. Atualidades Ornitológicas. Olinda, n.125, p. 1-15, maio/junho.2005.

PIVETTA, K. F. L.; SILVA FILHO, D. F. S. Arborização Urbana - Boletim Acadêmico: Série Arborização Urbana. Jaboticabal, SP: UNESP/FCAV/FUNEP, 2002.

REIS, A; ANJOS, A.; LEISSA, A. P.; BECHARA, F. C. Critérios para a seleção de espécies na arborização urbana ecológica. Sellowia. V. 53, n. 55, p. 51-67, 2003.

RODIGHIERO, D. A. ; SILVA, L. M. . Infra-estrutura urbana e arborização em três bairros de Pato Branco/PR. In: XII Seminário de Iniciação Científica e Tecnológica da UTFPR, 2007, Anais...Curitiba: UTFPR, CD-ROM.

SANTOS, N. R. Z.; TEIXEIRA, I. F. Arborização de Vias Públicas: Ambiente X Vegetação. Santa Cruz do Sul: Instituto Souza Cruz, 2001. 135p.

SILVA. L, M et al. Inventário da Arborização em duas Vias de Mariópolis/ PR. Revista da Sociedade Brasileira de Arborização Urbana. Piracicaba, v.3, n.1, p. 36-53. , mar. 2008.

SILVA, L. M. ; HASSE, I. ; MOCCELLIN, R. ; ZBORALSKI, A. R. . Arborização de vias públicas e a utilização de espécies exóticas: o caso do bairro centro de Pato Branco/PR. Scientia Agraria (UFPR), v. 8, p. 47-53, 2007.

ZILLER, S. R. Plantas Exóticas Invasoras: a Ameaça da Contaminação Biológica. Revista Ciência Hoje, n.178, 2001. Disponível em: http://www.cienciahoje.uol.com.br. Acesso em: 25/03/2007. 